\title{
Superelastic Collisions of Electrons with Excited $\mathrm{Mn}^{+}$
}

\author{
Fred Strobel and D. P. Ridge \\ Department of Chemistry and Center for Catalytic Science and Technology, University of Delaware, Newark, \\ Delaware, USA
}

Excited $\mathrm{Mn}^{+}$ions formed by electron ionization of $\mathrm{Mn}_{2}(\mathrm{CO})_{10}$ are deexcited in superelastic electron-ion collisions. The ions are held in the trap of a Fourier transform ion cyclotron resonance spectrometer and subjected to bombardment by an electron beam of varying energy. The population of excited $\mathrm{Mn}^{+}$ions after exposure to the beam is monitored by examining reaction of the trapped $\mathrm{Mn}^{+}$ions with $\mathrm{Cr}(\mathrm{CO})_{6}$. Charge transfer to form $\mathrm{Cr}(\mathrm{CO})_{6}^{+}$ is exothermic and efficient only for excited $\mathrm{Mn}^{+}$. It is found that deexcitation is readily observable for electrons with energies less than $2 \mathrm{eV}$. (I Am Soc Mass Spectrom 1990, 1 , 192-194)

$\mathrm{L}$ ow-energy electron impact (EI) excitation of neutral species [1] and ions [2] can produce elecItronic transitions that are optically forbidden. The excited states produced by EI may therefore be metastable. This suggests that the reverse process, EI on metastable excited state species, can produce relaxation to the ground state and a superelastically scattered electron. Observation of these deexcitation processes poses a number of experimental difficulties. First, a sufficiently large population of excited ions must be generated. Second, a means for monitoring the depletion of that population must be available. Third, it must be possible to attribute the excited state loss unequivocally to EI. Because of these difficulties, relatively few observations of superelastic electron scattering by ions have been reported. The only example we find in the recent literature is Walker and Bonin [3]. We report here an experiment in which each of these problems is solved using mass spectrometric techniques.

The approach is suggested by experiments using ion cyclotron resonance (ICR) to follow EI excitation of neutral particles [4] and ions [5]. Inelastic electron-neutral particle collisions have been examined by taking advantage of the efficient trapping in the ICR cell, the maximum in the excitation cross section at electron energies near threshold, and the large cross sections for low-energy electron attachment of such species as $\mathrm{CCl}_{4}$. If the energy of a colliding electron is near the energy of an excited state of the neutral species, then the probability for excitation is usually near its maximum. The resulting inclastically scattered electron has near-zero energy and is caught in the ICR trap. The trapped electron is efficiently captured by a scavenger such as $\mathrm{CCl}_{4}$ and converted to an anion

Address reprint requests to D. P. Ridge, Department of Chemistry and Biudenustry, University of Delaware, Newark, DE 19716. that can be monitored by its ICR signal. The anion signal then exhibits maxima at electron energies corresponding to energies of excited states of the neutral species. Electron exchange makes singlet-triplet transitions possible on EI, so excitation of low-lying triplet states of neutral species has been observed in this way.

The strong magnetic field required for ion cyclotron resonance mass spectrometry (ICR/MS) collimates the electron beam and confines the EI-produced ions. The ions are thus susceptible to EI if the electron beam current is large enough. It has been shown that such trapped ions can be further ionized or fragmented by ion-electron collisions [5]. We report here evidence that EI deexcitation of excited ions can be observed by using ICR/MS.

We recently showed that an excited state of $\mathrm{Mn}^{+}$ produced by $\mathrm{EI}$ on $\mathrm{Mn}_{2}(\mathrm{CO})_{1 \mathrm{n}}$ is sufficiently long-lived to be detected by its chemistry using ICR/MS [6]. It is this excited species that we examine in the present report.

\section{Experimental}

The experiments were performed on a Nicolet FTMS-2000 ICR spectrometer [7]. For a review of Fourier transform ICR techniques, see Comisarow and Buchanan [8]. The instrument consists of two 2-in. cubic cells that have one face in common. The cells are differentially pumped through a 3-mm-diameter opening in the center of the plate that forms the common face. The ionizing electron beam passes along the central axis of the two cells, Iraversing the upening in the common plate. The magnetic field is parallel to the electron beam and is provided by a superconducting solerwidal magnet that has a field strength of $3.03 \mathrm{~T}$. The magnetic field constrains ions to cyclotron orbits around the field lines. Ion motion parallel to the field is constrained by potentials on the cell plates perpen- 


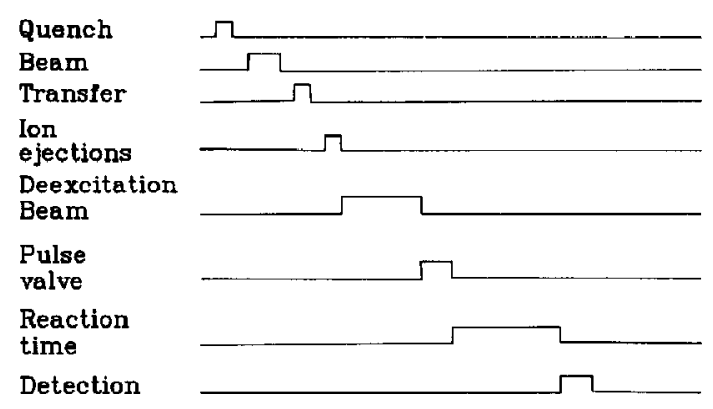

Figure 1. Sequence of experimental steps used to observe EI deexcitation of electronically excited $\mathrm{Mn}^{+}$. Ions are quenched from the cell: electron beam forms ions in the source; ions are transferred to the analyzer; other ions are ejected isolating $\mathrm{Mn}^{+}$; valve opens, admitting $\mathrm{Cr}(\mathrm{CO})_{6}$, which reacts with the ion; and the products are detected

dicular to the field. Positive ions are trapped by small positive trapping voltages $(1 \mathrm{~V})$ on those plates, and negative ions are trapped by small negative voltages. The potential on the common plate controls motion between the cells. If the common plate has zero potential, then the ions are free to move between the cells. If the common-plate potential is raised to the trapping voltage, then the ions cannot move from one cell to the other.

The experimental sequence is illustrated in Figure 1. The $\mathrm{Mn}^{+}$ion is formed in one cell, the source cell, by $70-\mathrm{eV}$ EI on $\mathrm{Mn}_{2}(\mathrm{CO})_{10}$, which is present in that cell at a nominal pressure of $1 \times 10^{-7}$ torr. The ions formed by EI are then transferred into the adjacent analyzer cell, which is at a nominal pressure of $2 \times 10^{-9}$ torr. Ions other than $\mathrm{Mn}^{+}$are ejected from the cell by irradiating them at their cyclotron frequency so that their cyclotron orbits grow sufficiently that they strike the walls of the cell and are neutralized [9]. The isolated $\mathrm{Mn}^{+}$is then exposed to a second burst from the electron beam. This burst lasts $0.25 \mathrm{~s}$, and the beam current is $1 \mu \mathrm{A}$ measured at a collector after it has traversed the cell. The energy of the beam is varied. After the second electron beam burst, a probe gas is admitted to the analyzer cell through a computer-controlled valve [10]. The probe gas is $\mathrm{Cr}(\mathrm{CO})_{6}$, which undergoes charge transfer with $\mathrm{Mn}^{+}$in the excited state but not with the ground-state ion. A mass spectrum is acquired $1 \mathrm{~s}$ after the valve opens to admit probe gas. The intensity of the $\mathrm{Cr}(\mathrm{CO})_{6}^{+}$signal is taken as a measure of the amount present in the excited state. The pressure of the probe gas drops to background $\left(2 \times 10^{-9}\right.$ torr) in about $1 \mathrm{~s}$. The elapsed time from initial ion formation to spectrum acquisition is less than $1.5 \mathrm{~s}$. Radiative decay of the excited state is negligible in that time.

The electron gun consists of a filament biased relative to ground. There is a grid between the cell and the filament that can be used to shut off the electron beam. After the beam traverses the cell, the current is collected and measured. The bias on the filament plus one-half the trapping voltage is taken as the electron

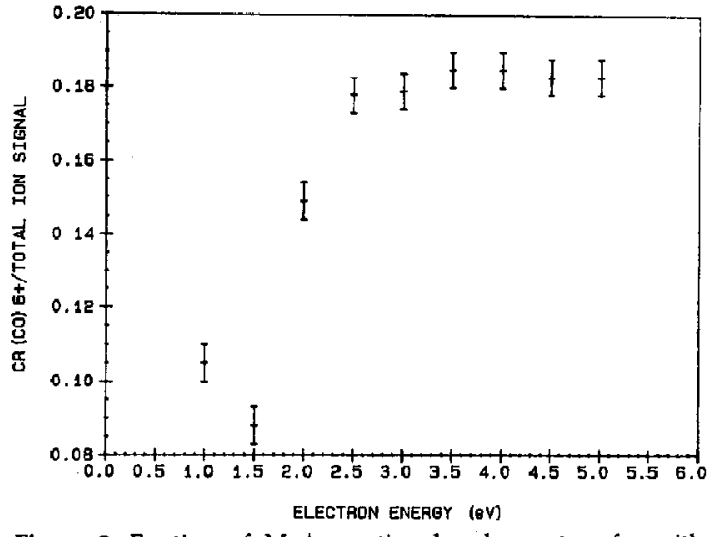

Figure 2. Fraction of $\mathrm{Mn}^{+}$reacting by charge transfer with $\mathrm{Cr}(\mathrm{CO})_{6}$ plotted against the energy of an electron beam to which the $\mathrm{Mn}^{+}$is exposed before reaction. The energy of the electron beam is taken as the filament bias plus one-half the trapping voltage.

energy $E_{\mathrm{i}}$. Near the trapping plates the electrons will be accelerated by the trapping potential and have energies larger than that acquired from the filament bias. Most of the collisions, however, will occur at energies near that nominal energy. This effect together with the fact that the ions are emitted by a hot filament suggests an estimated uncertainty in $E_{i}$ of $\pm 0.3 \mathrm{~V}$. The estimated correction for the space potential of the electron beam [5a] is less than $0.1 \mathrm{eV}$ for the present configuration.

\section{Results and Discussion}

The deexcitation process is

$$
\mathrm{Mn}^{+*}+\mathrm{e}\left(E_{\mathrm{i}}\right) \rightarrow \mathrm{Mn}^{+0}+\mathrm{e}\left(E_{\mathrm{f}}\right)
$$

where $E_{\mathrm{i}}$ and $E_{\mathrm{r}}$ are the initial and final kinetic energies of the electron. In Figure 2 are plotted the relative concentrations of $\mathrm{Cr}(\mathrm{CO})_{6}^{+}$formed by charge transfer from $\mathrm{Mn}^{+*}$ after exposure of the trapped $\mathrm{Mn}^{+}$to an electron beam of energy $E_{\mathrm{i}}$. The drop in $\operatorname{Cr}(\mathrm{CO})_{6}^{+}$signal intensity at low $E_{\mathrm{i}}$ indicates that the $\mathrm{Mn}^{+*}$ precursor to $\mathrm{Cr}(\mathrm{CO})_{6}^{+}$has been converted to $\mathrm{Mn}^{+0}$ by process 1. At higher values of $E_{\mathrm{i}}$, the population of $\mathrm{Mn}^{+*}$ is unaffected by exposure to the electron beam.

The energies of low-lying electronic states of $\mathrm{Mn}^{+}$ are given in Table 1. The results of Elkind and Armentrout [11] and those of Strobel and Ridge [6] indicate

Table 1. Some electronic states of $\mathrm{Mn}^{+}$

\begin{tabular}{lcc}
\hline Stale & Conliguration & Energy (eV) \\
\hline \hline${ }^{5} S$ & $3 d^{5} 4 s$ & 0.00 \\
${ }^{5} S$ & $3 d^{5} 4 s$ & 1.17 \\
${ }^{5} D$ & $3 d^{6}$ & 1.78 \\
${ }^{5} G$ & $3 d^{5} 4 s$ & 3.41 \\
\hline
\end{tabular}

Source: Corliss, C.: Sugar, J. J. Phys. Chem. Ref. Data, 1977, 6, 1253. 
that $\mathrm{EI}$ on $\mathrm{Mn}_{2}(\mathrm{CO})_{10}$ produces $\mathrm{Mn}^{+}$, approximately $20 \%$ of which is in excited states. Most of the excited state population is in the ${ }^{5} \mathrm{~S}$ state. The radiative lifetime of the predominant excited state is at least $5.8 \mathrm{~s}$. The data in Figure 2 suggest, then, that at an $E_{\mathrm{i}}$ of 2 $\mathrm{eV}$ and below the ${ }^{5} \mathrm{~S}$ state gives the ${ }^{7} \mathrm{~S}$ ground state and a superelastically scattered electron. The value of $E_{\mathrm{f}}$ would be $E_{\mathrm{i}}+1.17 \mathrm{eV}$.

The disappearance of the excited state could result from excitation from the ground state to a higher state with a short radiative lifetime. Such fluorescent states should have a $4 p$ electron so that transitions to lower states are parity allowed. The lowest state with a $4 p$ electron, however, is a $\left(3 d^{5} 4 p\right){ }^{7} P$ state, which at an energy of $3.6 \mathrm{eV}$ with respect to the ${ }^{5} S$ state cannot be involved in the deexcitation process.

We see no evidence for EI excitation of the ground state. Microscopic reversibility requires that at sufficiently low electron energies the superelastic deexcitation cross section must be much larger than the maximum in the excitation cross section. This accounts for the effect we are seeing. The excitation cross section may be too small to lead to observable excitation, whereas at lower electron energies the deexcitation cross section is large. It may be that excitation processes are followed by capture and deexcitation. Excitation at threshold produces a zero-energy electron that will be attracted to the excited ion. Immediate deexcitation of the ion by this electron might be particularly probable. This type of process might limit the efficiency of the collisional excitation.

There appears to be a maximum in the quenching cross section at about $1.5 \mathrm{eV}$. This minimum is reproducible and may result from competition between excitation of the ${ }^{5} S$ excited state to the ${ }^{5} D$ state and deexcitation.

Other systems are known to produce long-lived excited states and might be subject to a similar effect. Higher currents or longer exposures might result in the observation of collisional excitation processes in $\mathrm{Mn}^{+}$ or other systems. Experiments probing these possibilities are under way in our laboratory.

\section{Acknowledgment}

The authors thank R. J. Ridge for helpful discussions on superelastic electron atom collisions.

\section{References}

1. Trajmar, S; Cartwright, D. C. In Electron-Molecule Interactions and Their Applications; Christophorou, L. G., Ed.; Academic: Orlando, FL, 1984; vol. 1, PP 155-249.

2. (a) Phaneuf, R. A. In Atomic Processes in Electron-Ion and Ion-Ion Collisions; Brouillard, F., Ed.; Plenum: New York, 1986; pp 117-156. (b) Defrance, P. In Atomic Processes in Electron-Ion and Ion-Ion Collisions; Brouillard, F., Ed.; Plenum: New York, 1986; pp 157-184.

3. Walker, T. G.; Bonin, K. D. J. Chem. Phys. 1988, 89, 1358-1363.

4. Ridge, D. P.; Beauchamp, J. L. J. Chem. Phys. 1969, 51, 470.

5. (a) Freiser, B. S.; Beauchamp. J. L. Chem. Phys. Lett. 1976, 42, 380-382. (b) Cody, R. B.; Freiser, B. S. Anal. Chem. 1979, 51, 547. (c) Freiser, B. S. Int. J. Mass Spectrom. Ion Phys. 1980, 33, 263-267. (d) Fedor, L.; Cody, R. B.; Cooks, R. G.; Freiser, B. S. Int. J. Mass Spectrom. Ion Phys. 1981, 39, 55-64. (e) Cody, R. B.; Freiser, B. S. Anal. Chem. 1987, 59, 1054-1057.

6. Strobel, F.; Ridge, D. P. J. Phys. Chem. 1989, 93, 3375.

7. Cody, R. B.; Kinsinger, J. A.; Ghader, S.; Amster, I, J.; McLafferty, F. S.; Brown, C. E. Anal. Chim. Acta 1985, 178, 43-66.

8. Comisarow, M. B.; Buchanan, M. V. In Fourier Transform Ion Cyclotron Resuruance Muss Spectrometry: Principles and Applications; Comisarow, M. B., Buchanan, M. V., Eds.; ACS Symposium Series 359; American Chemical Society, Washington, DC. 1987; pp 1-20.

9. Comisarow, M. B.; Grassi, V.; Parisod, G. Chem. Phys. Lett. $1978,57,413-416$

10. (a) Sack, T. M.; Gross, M. L. Anal. Chem. 1983, 55, 2419-2421. (b) Carlin, T. J.; Freiser, B. S. Anal. Chem. 1983, 55, 571.

11. Elkind, J. L,; Armentrout, P. B. I. Chem. Phys. 1986, 84, 4862-4871. 